\title{
UM CERTO DESEJO DE LIBERDADE
}

Prof. Dr. Côn. Antônio Manzatto Jeni Bertoni Nimtz (eds.) $)^{1}$

\section{RESUMO}

A aproximação entre teologia e literatura já vem sendo feita há tempos nas instituições teológicas brasileiras, proporcionando já uma base hermenêutica segura para esse trabalho. O presente texto trabalha a relação entre teologia e literatura a partir de "Um certo Capitão Rodrigo", de Érico Veríssimo. A afirmação do valor da liberdade e da importância do compromisso, feitos por aquele texto, podem constituir importante campo para o diálogo entre a arte literária e a reflexão da fé.

Palavras-Chave: Teologia, Literatura, Liberdade.

\begin{abstract}
The approach between theology and literature has been comming just from a long time in the brasilian theology institutions, giving a secure hermeneuthic base for this work. The actual text deals with the relation between theology and literature from a view point of Erico Verissimo's "Um certo Capitão Rodrigo". The affirmation of the value of liberty and the importance of the commitment done by those text can be an important field for the dialogue between a literary art and the reflection of the faith..
\end{abstract}

Key words: Theology, Literature, Liberty.

\footnotetext{
${ }^{1}$ Este texto foi elaborado no final do curso que teve em vista algumas possibilidades de relações entre teologia e literatura no programa de pós-graduação em teologia da Faculdade de Teologia Nossa Senhora da Assunção, no ano de 2005. Participaram da elaboração do texto, como co-autores, os seguintes alunos: Edevilson de Godoy, José Antonio Cruz, José Henrique do Carmo, Nei de Oliveira Preto, Nelson Mendes Vasconcelos, Pedro Donizeti de Campos e Ricardo Antonio Pinto.
} 


\section{INTRODUÇÃO}

Há tempos vêm sendo trabalhadas no Brasil, e com real proveito e interesse, as relações entre teologia e literatura, sobretudo nos programas de pós-graduação em Ciências da Religião e Teologia e em grupos de pesquisa multi e pluridisciplinares. Isso revela não apenas o interesse do tema e sua importância, enquanto estudo de manifestações culturais que podem ajudar no trabalho de compreensão da cultura, da sociedade e da humanidade, como também na elaboração da reflexão teológica. Muitos autores estão sendo estudados, muito trabalho de pesquisa está sendo feito na busca da produção de conhecimento que permita melhor entender a vida do ser humano no mundo. O resultado deste trabalho está expresso em múltiplas publicações e na elaboração de diversas teses e dissertações acadêmicas ${ }^{2}$ em diversos lugares.

De certa forma, nossa Faculdade foi pioneira no trabalho desse tema, pois aqui, já em 1993, se organizava um curso sobre teologia e literatura. Voltou-se agora ao tema como resultado da reorganização do grupo que o trabalha em nosso Programa de Pós-graduação. O texto escolhido para a elaboração da reflexão foi "Um certo Capitão Rodrigo", parte da grande obra "O tempo e o vento" de Érico Veríssimo, e é esse trabalho que apresentamos a seguir.

\section{SOBRE TEOLOGIA E LITERATURA}

A literatura é uma arte e seu criador um artista. Sua primeira relação é com o Belo, sendo o escritor o artista da palavra, que com essa ferramenta esculpe imagens simbólicas no sentido de pintar, com as cores de estilo, ambiente e personagens de sua produção. "Artesão que é, trabalha

\footnotetext{
${ }^{2}$ Cite-se, como exemplo, Antonio Manzatto, Teologia e literatura. Loyola, São Paulo, 1994; VÁRIOS, Teologia e literatura. Cadernos de pós-graduação 9. UMESP, São Bernardo do Campo, 1997; Antonio Carlos de Melo Magalhães, Deus no espelho das palavras. Paulinas, São Paulo, 2000. Também vários trabalhos acadêmicos contribuíram para o estabelecimento e amadurecimento dessa reflexão, como, por exemplo, Jeni Bertoni Nimtz, O teocentrismo no barroco brasileiro; São Paulo, 2003, PFTNSA, Tese doutoral; Clademilson F. Paulino da Silva, Liberdade e sofrimento, São Bernardo do Campo, 2005, Dissertação de Mestrado, UMESP; Cléber Diniz Torres, A dimensão religiosa da cultura na poesia de Vinícius de Moraes, São Bernardo do Campo, 2006, Dissertação de Mestrado, UMESP; Evandro César Cantaria da Silva, O judaísmo encalacrado: mística e religião em A Hora da Estrela, de Clarice Lispector, São Bernardo do Campo, 2006, Dissertação de Mestrado, UMESP.
} 
o vocabulário de tal maneira a transferir-lhe a essência da arte, cuja habitação está nas emoções provocadas pelos sentimentos que vêm do contato sensível com o mundo e que se exprimem nas cores, nas linhas, nos sons, nas palavras" 3 .

É assim que a literatura se define, como obra de artista, como trabalho elaborado pelo coração que percebe e sente os fatos, mais do que pelo intelecto que raciocina e reflete sobre eles. Portanto, para que não se tenha uma falsa compreensão do valor literário de uma obra, sobretudo em sua relação com os temas teológicos que dali podem ser trabalhados, convém que o dado lingüístico seja trabalhado convenientemente. Quando se depara com um tema a partir do discurso científico, a reação provocada é uma; quando se depara com o mesmo tema a partir do discurso literário, a reação é outra, muito mais visceral. "O uso científico da linguagem é direto, disseca o fato, torna unívoca a interpretação ao ligar o fato ou fenômeno a uma determinada forma de interpretá-lo. Em oposição a ele, o uso literário da linguagem é conotativo, isto é, repleto de associações e ambigüidades. A literatura caminha, portanto, entre a linguagem científica - sem querer ser dissecadora e unívoca - e a linguagem cotidiana - sem querer dispensar uma sistematização do mundo, uma organização do caos social e religioso"4.

O fato de a literatura apresentar um discurso diferente da discussão acadêmica, já que traz o dado de uma realidade que pode ser compreendida, inclusive à luz da fé como experiência cristã vivida, permite dizer que "a literatura se encontra nas fronteiras dos saberes, incorporando crítica e estética, juízo e simbolismo, história e mito, ciência e poesia" ${ }^{5}$. Dessa forma, em relação com a literatura, a teologia, como ciência da fé, lê, estuda e analisa um texto, seja ele religioso ou literário, para dele extrair o fato teológico, que pode acontecer em sentido literal, analógico, tropológico e anagógico ${ }^{6}$.

Além do fator lingüístico, convém lembrar a importância de se afirmar uma "antropologia literária", pois a literatura deve ser compreendida dentro

\footnotetext{
${ }^{3}$ Silvio Romero e João Ribeiro, Compêndio de história da literatura brasileira. Rio de Janeiro: Francisco Alves, 1990, p. 25.

${ }^{4}$ Antonio Carlos de Melo Magalhães, Deus no espelho das palavras. São Paulo: Paulinas, p. 122-123.

${ }^{5}$ Idem, Ibidem.

${ }^{6}$ Cf. Stefano Flores e Túlio Coffi. Dicionário de Espiritualidade. São Paulo: Paulinas, 1993, p. $1135-1136$.
} 
de sua relação com o mundo e o sentido da existência humana. Exatamente aqui - uma leitura da realidade onde habita a complexidade das relações humanas e do instigante porquê da vida - repousa o maior interesse teológico da literatura ou, dito de outra maneira, a expressão literária torna-se uma nova forma de compreensão do fazer teológico. Assim, a "literatura é a scientia nascida da experientia, que nunca é vana, devido à sua relação com a apropriação real e pessoal da verdade"7.

O referencial antropológico do discurso literário pode ser, assim, o local onde repousa o interesse teológico maior de uma obra literária, o desafio maior à pesquisa científica; é teológico o matiz com o qual se procura descobrir o mistério velado pelo estilo e pela arte do escritor, que aponta para o surgimento da pessoa no mundo. Ao teólogo cabe, pois, fundamentar uma reflexão de fé nas unidades semânticas presentes no jogo das cenas de ficção da obra literária, buscando penetrar no universo espiritual de quem as evidenciou e, assim, deixar-se conduzir por uma compreensão crítica da fé, que inclusive pode estar introjetada na personagem literária, mas que, de qualquer modo, repousa sobre o significado ao qual o texto literário conduz.

A literatura, em prosa ou em verso, goza de inteira liberdade no que se refere às normas ditadas pela ciência e, por isso mesmo, não é, nem pode ser, mera veiculação de conceitos teológicos. Antes, ela é uma apresentação crítica do mundo a partir do trabalho artístico do escritor que, assim, expressa uma "cosmovisão" e uma leitura do que significa existir como ser humano nesse mundo. Aqui o interesse da teologia que pode, então, aprender do discurso literário e realizar seu trabalho de reflexão crítica da fé a partir dos elementos que lhe são trazidos pela obra de arte.

Assim, a literatura é vista como o lugar de expressão e encontro da reflexão, do pensar crítico, do sentir e do agir do humano em todas as suas dimensões, aí incluindo a dimensão religiosa. No entanto, o interesse de uma obra literária - e veremos isso com Um certo Capitão Rodrigo - não se esgota na abordagem explícita da temática religiosa, mas se aventura pela temática humana, pura e simplesmente, já que é aí que a reflexão teológica vai nutrir-se para o trabalho de sua elaboração.

Os personagens de Érico Veríssimo, no caso específico de Um certo Capitão Rodrigo, são criaturas de ficção e, portanto, não históricos. Mas

\footnotetext{
${ }^{7}$ Idem, Ibidem.
} 
são verdadeiros por revelarem uma maneira de existir e de construir sua humanidade na habitação do mundo da ficção, símbolo do mundo concreto no qual existimos. Nessa linguagem metafórica ou parabólica, a reflexão teológica busca compreender a afirmação de humanidade e beber a seiva que the permite, refletindo sobre o ser do humano, colocar-se em relação de conhecimento com o ser divino.

\section{SOBRE O AUTOR}

Érico Veríssimo é um dos grandes nomes da literatura brasileira que dispensa comentários e apresentações. Digamos apenas que ele é gaúcho, nascido em Cruz Alta (RS) em 1905. Cedo, manifesta sua vocação literária. A década de 30 marca o desabrochar de sua criatividade, com o aparecimento de seu primeiro romance, Clarissa (1933), e o de seu primeiro grande sucesso, Olhai os lírios do campo (1938). É autor de numerosa obra literária, a qual consta de livros infantis, contos e romances. Foi membro da Academia Brasileira de Letras, tornando-se bastante conhecido por sua grande obra O Tempo e o Vento cujo trabalho de redação, iniciado em 1947, veio a ser publicado em 1962. Sua última obra foi Solo de Clarineta, livro de memórias cujo segundo volume foi publicado postumamente, logo depois de sua morte, em 1975.

Embora cidadão do mundo, Veríssimo sempre escreveu a partir de sua realidade brasileira, procurando entender e apresentar a alma de seu povo. Em especial, se consagra à apresentação da sociedade gaúcha, sobretudo em O Tempo e o Vento, obra na qual narra a epopéia da formação do Rio Grande do Sul. É exatamente esse seu mergulho no concreto da vida do povo gaúcho que o torna capaz de produzir uma obra com características de universalidade.

Sempre foi um combatente da liberdade. Viveu não apenas a realidade das duas guerras mundiais (1914-18 e 1939-45), mas também conheceu a ditadura do Estado Novo (1937-45) e, depois, a ditadura militar do Brasil (1964-85). Nunca hesitou em tomar a defesa da liberdade de expressão, de pensamento e de produção artística. Juntamente com Jorge Amado, pronunciou-se veementemente contra a censura na época da ditadura militar, ameaçando não mais publicar no Brasil se a censura continuasse fazendo suas vítimas e prejudicando o trabalho de criação dos artistas e escritores brasileiros. Em plena ditadura militar, publica Incidente em Antares (1971), 
depois de ter publicado O Prisioneiro (1967), criticando a presença norteamericana na guerra do Vietnã. É, pois, um escritor engajado, que não hesita em abordar em suas obras uma temática política e engajada.

\section{SOBRE A OBRA}

Sua obra O Tempo e o Vento é constituída de 3 partes: O Continente (2 volumes), O Retrato (2 volumes) e O Arquipélago (3 volumes), contando a epopéia da família Terra-Cambará e, através dela, a da formação do Rio Grande do Sul. Um certo Capitão Rodrigo ${ }^{8}$ é uma pequena novela que faz parte do primeiro volume de $\mathrm{O}$ Continente, primeira parte da trilogia de $\mathrm{O}$ tempo e o vento. Foi publicado separadamente do restante do romance na década de 70 . A primeira edição teve 40 reimpressões, o que marca o sucesso da obra.

Trata-se do terceiro episódio do romance, sendo que a ação se inicia em 1828, quando Rodrigo Cambará chega à cidade de Santa Fé, vindo de muitas guerras. Nos episódios anteriores, se apresentava a origem da família Terra. Na metade do século XVII nasce na Missão de São Miguel um mestiço, Pedro Missioneiro, de mãe índia e pai branco. Criado pelos jesuítas da missão, de lá Pedro foge quando, em 1756, começa a destruição dos territórios das missões do Rio Grande do Sul. Algum tempo depois, Pedro encontra-se com a família de Ana Terra, onde é acolhido. Eles acabam se apaixonando; porém, ao ter notícias do romance e descobrir sua filha grávida, Maneco Terra ordena que seus filhos matem o mestiço. Ana Terra assume a responsabilidade de criar sozinha seu filho. Quando bandidos atacam e destroem a estância de seu pai, vê-se obrigada a seguir, com as mulheres da família, para as terras do coronel Amaral, que fundava a vila de Santa Fé. Lá se estabelece com sua família. É nesta cidade que aparece, tempos depois, Rodrigo Cambará que se apaixona por Bibiana Terra, neta de Ana Terra. Aí inicia-se, propriamente, a ação de Um certo Capitão Rodrigo.

Chegando em Santa Fé, vindo de muitas guerras, Rodrigo se torna amigo de Juvenal Terra. Ao conhecer a irmã deste, Bibiana, por ela se apaixona e ela também por ele. Mas há oposição: a do pai de Bibiana,

\footnotetext{
${ }^{8}$ Neste estudo, seguimos a seguinte edição: Érico Veríssimo, Um certo Capitão Rodrigo, Companhia das Letras, $3^{a}$. Edição, 2005. O texto foi estabelecido pelo Acervo Literário de Érico Veríssimo, da Puc de Porto Alegre.
} 
Pedro Terra e a de Bento Amaral, filho do coronel Ricardo Amaral, que também quer se casar com a moça. Devido a um desentendimento numa festa, Rodrigo e Bento se batem em duelo e, num ato de traição, Rodrigo é seriamente ferido. É tratado e cura-se na casa de Pedro Terra. Casa-se com Bibiana, estabelece-se numa venda em Santa Fé, vê o nascimento de seu filho Bolívar. Depois de algum tempo, começa a entediar-se daquele estilo de vida, ele que sempre havia vivido livre, "com o vento no rosto". Decai moralmente, trai sua esposa, perde-se no jogo... nem assiste à morte de sua filha, Anita. Desse momento em diante, regenera-se e torna-se novamente pai e marido com responsabilidade. É o momento em que estoura a Revolução Farroupilha, também conhecida como Guerra dos Farrapos. Juntando-se aos revoltosos, parte para a luta. Tempos depois, volta a Santa Fé com as tropas rebeldes para tomar a cidade. Encontra-se pela última vez com sua esposa, já que será morto no ataque desferido para tomar o casarão do coronel Amaral.

Percebe-se no texto a vinculação com o momento literário da segunda fase do modernismo (1930-1945), também conhecido como ciclo do Romance de 30 , onde o autor apresenta temas regionais e o emprego de uma linguagem própria de determinada localidade. Aparecem, então, os temas ligados a uma visão positiva do humano em contraste com elementos negativos vindos de outra antropologia; as questões sobre o amor à vida, ligadas às outras sobre a defesa dos ideais pelos quais vale a pena lutar; a apresentação - ousada - do "arquétipo" do ser humano brasileiro, na figura do "gaúcho ideal", ou seja, autêntico, livre, franco e irreverente, mas generoso, solidário e lutador, capaz de amar e de dar sua vida pelos valores nos quais acredita e pelas pessoas que ama.

\section{SOBRE OS PERSONAGENS}

Narrando as aventuras de Rodrigo Cambará e da família Terra em Santa Fé, Érico Veríssimo vai traçar a epopéia da formação do povo gaúcho e da história do Rio Grande do Sul. Não se trata apenas de relembrar os fatos que formaram o início da história daquela região, como as missões e reduções jesuítas, a chegada dos colonos alemães ou as muitas guerras e revoluções que por ali aconteceram, como a Revolução Farroupilha ou as lutas contra "os castelhanos" pelo estabelecimento das fronteiras com o Uruguai e Argentina. Mais que isso, o autor retrata a alma gaúcha que vai 
sendo formada ao longo de sua história, apresentando seus sonhos, projetos e utopias, como também seus valores e referenciais de vida.

Rodrigo Cambará é um dos personagens mais fortes e marcantes não apenas de $\mathrm{O}$ Tempo e o Vento, mas de toda a literatura brasileira. Ele encarna o ideal gaúcho de liberdade e coragem, através de seu comportamento de luta e destemor. Formado em guerras, Rodrigo luta não apenas porque "guerra é coisa de homem" ou porque "na guerra tudo se ajeita", mas porque a luta é a forma de construir a liberdade pessoal e social. Assim, suas guerras não são apenas violência e destruição, mas o caminho pelo qual se constrói a vida, com coragem e alegria. Afinal, "viver é muito bom".

Outros personagens importantes aparecem na trama, como Juvenal e Pedro Terra e, claro, Bibiana, a mulher que crê no amor e vive para a família, comprometendo-se a construir, dentro do lar, o que o marido tenta construir na sociedade. Através do trabalho, da luta, da política e da guerra. Bibiana é a autêntica mãe de família que guarda a fibra de muito tempo de luta; não se desespera diante do sofrimento e, formada por ele, com coragem e paixão, faz frente à vida.

Personagem importante em Um certo Capitão Rodrigo é o Padre Lara. Não é protagonista da trama, mas é personagem importante. O interesse teológico do estudo da obra, porém, não repousa no fato de ter um personagem que seja padre, ainda que se admita que o olhar do teólogo seja atraído pelo personagem religioso. Padre Lara, cedo, vai tornar-se amigo de Rodrigo, com quem tem interessantes discussões, e vai freqüentar sua casa, como freqüenta a do coronel Amaral e a de Pedro Terra. Trata-se da apresentação da figura do pastor, afirmando a importância da presença da religião, ainda que de forma um tanto ambígua, na formação do povo gaúcho.

\section{ASPECTOS LITERÁRIOS}

O título da obra já apresenta aspectos interessantes para a reflexão. Tem-se o artigo um, o pronome indefinido certo e o qualificativo capitão. Todos qualificam o personagem Rodrigo e, através deste expediente, Veríssimo define não um homem, mas o homem, isso agregado ao fato de que o uso da expressão um certo permite trabalhar com o desconhecimento da origem e da personalidade de Rodrigo Cambará, o que vai permitir que o comportamento do personagem seja, no mais das vezes, surpreendente. 
O fato de ser capitão, por outro lado, permite estabelecer relação com a realidade de guerras e lutas, com as quais o personagem esteve envolvido antes e depois de sua chegada a Santa Fé.

O nome Rodrigo parece vir das façanhas do conquistador espanhol Rodrigo Diaz de Bivar, conforme afirmação do autor que diz "não saber explicar de onde nasceu o capitão Rodrigo Cambará, embora desconfie que a figura do Cid Campeador, também denominado Rodrigo, tenha-o inconscientemente ajudado em algo"9. Por outro lado, o sobrenome Cambará parece ter sido cuidadosamente escolhido, já que, além de sua sonoridade, designa "árvore de duro lenho"10, o que demonstra já certos aspectos do que será a personalidade do Capitão Rodrigo Cambará, qualificado no romance como um "homem impossível", "patife simpático" ou "pecador, mas bom companheiro". Assim, ele será alguém que "não tinha meio termo: ou era risada ou choro, beijo ou bofetada, festa ou velório", mas capaz de amizade, de dedicação e solidariedade, ao mesmo tempo em que questiona e critica a vida, a política, a Igreja.

Do começo ao fim da história, Veríssimo parece querer mostrar um homem autenticamente crítico em relação aos valores propostos pela sociedade de então. Com isso, ele afirma a realidade e o valor da liberdade. $O$ fato acontece, por exemplo, com relação ao casamento que, na época, eram arranjados pelos interesses das famílias, independentemente da vontade dos nubentes; Rodrigo e Bibiana, mesmo enfrentando a oposição do pai da moça, Pedro Terra, vão se casar. Aos poucos, aquele homem valente, conquistador, típico desbravador dos pampas, vai tornar-se amado pelos habitantes de Santa Fé e pelos descendentes de Ana Terra, pois sua personalidade de "homem de bem" se manifesta em pensamentos e desejos grandiosos, como a busca de um mundo novo, superando as dores e injustiças...eis então os ideais de Rodrigo: dar um pedaço de chão para cada peão, para cada negro, para

\footnotetext{
${ }^{9}$ Rodrigo Diaz de Bivar foi figura contraditória das lutas de reconquista da Península Ibérica então em posse dos muçulmanos. O texto original de suas façanhas, denominado "Cantar Del Mio Cid", jogral anônimo, ganhou versão literária em manuscritos já de 1307, atribuídos a um certo Per Abbat, texto que transformou o guerreiro em herói nacional, embora continuamente trocasse de lado. Mais tarde, em 1636, Pierre Corneille também o transformou em herói de sua tragédia, denominada "Le Cid", inspirando-se em uma versão dramática anterior, "Las Mocedades Del Cid", de Guillén de Castro. Parece residir aqui a motivação para Veríssimo escolher o nome de Rodrigo para seu pesonagem. Cf. Érico Veríssimo, Cadernos de Literatura. Instituto Moreira Salles, no. 16, novembro de 2003, p. 107.

10 Idem, Ibidem, p. 89.
} 
cada índio; acabar com as línguas diferentes; fazer o mundo menor, para atravessá-lo a cavalo; eliminar a velhice e o sofrimento a ela ligados.

A trama da história de Veríssimo mescla ficção e acontecimentos históricos. Os fatos históricos aparecem na narrativa na busca da reconstrução da cultura brasileira a partir da formação do Rio Grande do Sul. Situa-se entre 1745 - período das guerras de fronteira e do estabelecimento das primeiras estâncias gaúchas - e 1895, data da reestruturação da república do Rio Grande do Sul. No texto, há indicações claras sobre a Guerra dos Farrapos, liderada por Bento Gonçalves e a acusação levantada contra ele de querer anexar o Rio Grande do Sul ao Uruguai. Há também referência a outros tumultos acontecidos por conta da miséria, da morte de escravos, da alta de impostos, da distância da corte com relação aos trabalhadores do sul. A ficção apresenta a cidade de Santa Fé como "modelo" da organização da sociedade gaúcha, com a família do Coronel Amaral determinando o poder político-econômico, o Padre Lara representando a força da Igreja local, a família Terra-Cambará fazendo girar em torno de si o enredo da narrativa. Dessa mistura de elementos de ficção e história, aparecem lições de vida, no mais das vezes ligadas ao apego à terra, à família, à solidariedade.

Tais considerações levam Veríssimo a apresentar, de maneira positiva, o humano que habita o sul do Brasil em sua luta pelo estabelecimento de uma identidade própria e de um intenso desejo de liberdade. Não foge, contudo, aos problemas de discriminação. É o que se pode verificar através do entendimento do personagem Rodrigo, o qual, ao chegar em Santa Fé, não é aceito pelas autoridades locais, representadas pelo Coronel Amaral, nem pelos simples e tradicionais, como Pedro Terra. E isso, por representar a chegada de novos tempos, de aventura e insegurança, desafios que são vistos como perigosos pela tradição mais estrita. Aos poucos, no entanto, Rodrigo conquista toda a população através de sua generosidade e coragem. A discriminação aparece, também, no episódio da chegada dos colonizadores alemães a Santa Fé, de quem se dirá que "estrangeiro é bicho esquisito". Nem o Padre Lara escapa de uma visão preconceituosa com relação a eles, que poderiam "ser protestantes".

O quadro geral, se assim se pode dizer, é o da sociedade tradicional sacudida pela chegada de não apenas novas pessoas, mas nova ordem que traz novos relacionamentos. A antiga ordem deve ceder lugar àquela que chega, ou ao menos compor com ela. O novo, com sua dose de coragem 
e aventura, é trazido por Rodrigo e aceito por Bibiana; o antigo é representado pelo Coronel daquelas terras, cujo poder será retirado pela revolta popular que conquista o Casarão; por Pedro Terra, o honesto trabalhador tradicional que, no entanto, resiste às mudanças, mas terá que aceitá-las; por Padre Lara, o representante da religião que, se apegado à tradição das afirmações dogmáticas, será muito mais aberto em termos práticos, abrindo seu coração face aos novos acontecimentos e à realidade da vida das pessoas. Uma sociedade em mudanças, portanto, onde o novo aparece (Rodrigo) e se mistura com o antigo (família Terra), dando origem ao Brasil que conhecemos e no qual vivemos.

\section{ASPECTOS TEOLÓGICOS}

Vários são os aspectos teológicos que podem ser pensados a partir da obra de Veríssimo. "O símbolo dá a pensar", dizia Paul Ricoeur. Assim com o texto de Um certo Capitão Rodrigo que, como metáfora literária do real, pode conduzir o pensamento a uma série de reflexões sobre a realidade, apesar de sua característica de obra de ficção. $O$ arrependimento dos pecados, a questão dos sacramentos, a ação pastoral da Igreja, o papel da religião na vida das pessoas e outros pontos podem ser enfocados, teologicamente, a partir da literatura de Érico Veríssimo, aqui apresentada. Mesmo o personagem religioso da trama, o Padre Lara, pode ser um importante elemento para essa reflexão. Ele não é protagonista da trama, como já foi dito, mas personagem importante que acompanha o desenrolar da história, mostrando uma presença de religioso, e por extensão, de Igreja entendida como ação pastoral, fato que não é desprovido de interesse.

Cremos, no entanto, que nenhuma reflexão será tão densa e tão importante quanto aquela sobre a liberdade. Com efeito, Um certo Capitão Rodrigo parece ser uma metáfora da liberdade, conduzindo a uma reflexão sobre ela. O personagem principal do romance, Rodrigo Cambará, é um homem acostumado à liberdade, representada normalmente pelo cavalgar livre pelas coxilhas dos pampas, pelo seu pouco senso moral, pelo desafio às normas estabelecidas. Cresceu livre, participou de muitas guerras, andou livre pelo mundo afora... assim ele entendeu essa sua vida, vivida no gosto da liberdade, o que gerou uma dificuldade enorme em estabelecer-se, em aquietar-se, em ganhar seu sustento através de um emprego ou de um trabalho na terra. Mesmo o casamento, para ele, fora uma espécie de prisão, 
de cerceamento da liberdade. Não que ele negue o valor do amor, da família e do casamento, ao contrário, mas a vida parada, pacata, repetitiva, causa estranheza a quem sempre andou pelos caminhos do mundo, acostumado ao gosto da novidade.

A questão crucial é que o texto parece querer dizer que a liberdade precisa ser buscada, cultivada, construída em constante processo. No momento em que se crê estar de posse da liberdade, ela se torna situação de prisão e opressão. Viver livre é viver construindo a liberdade, não estar de posse dela. As muitas lutas e guerras de Rodrigo Cambará não são outra coisa senão a construção de sua liberdade pessoal e social. As lutas, "coisa de homem", são o marco de sua busca de liberdade; "coisa de homem", porque o humano se constrói exatamente aí, na luta pela liberdade. Eis a razão da crítica, não tão velada assim, de Veríssimo a toda espécie de prisão e opressão, de exercício da força que impede a liberdade do ser humano. A crítica é mesmo voltada a uma religião que assume ares opressores, desconhecendo que o humano deve construir-se em liberdade. A figura do Padre Lara, aqui, é bastante simbólica, representando o poder religioso tradicional, seu apego às formulações dogmáticas tradicionais e suas alianças também tradicionais, a fim de fazer com que a vida continue sempre da mesma maneira, como as estações do ano que não mudam nunca. Parece estar aí a segurança das pessoas; como as estações não mudam - o que dá segurança ao agricultor - assim os acontecimentos da vida também não devem mudar, mas repetir-se, mais ou menos da mesma maneira, geração após geração. No entanto, essa segurança não é mais que uma prisão, pois segura, prendendo. Contra ela, levanta-se Érico Veríssimo pela voz e pela ação de Rodrigo Cambará. Ele é como cavalo tinhoso, que não se deixa aprisionar. Honesto, não se entrega; vê a vida sempre como um desafio a ser vencido. Não é esse o significado do gesto que ele faz quando o Padre vem propor-lhe a absolvição no momento em que sua morte parece aproximar-se?

Desafio, não conformismo, ânsia de liberdade. Assim é o Capitão Rodrigo, assim Veríssimo enxerga o gaúcho, o ser humano em geral, em sua dignidade. Não há destinos prontos, poderíamos dizer, mas a história humana a ser construída. Isso é um desafio, um peso, mas também a afirmação da grandeza do ser humano, cuja identidade e grande dignidade estão em construir sua própria história. Não há definitivos na vida, repetições de acontecimentos, destino traçado: a cada um é dada a liberdade de construir sua 
existência na aventura de viver. "Cada um carrega o dom de ser capaz de ser feliz", diz o poeta. Érico Veríssimo, na linha do Romance de 30, afirma que a dignidade humana deve ser construída na liberdade da composição da história de cada pessoa e de cada povo.

Essa liberdade, assim compreendida, não é para ser confundida com irresponsabilidade. Ela traz no seu bojo um compromisso: se a vida é para ser construída na liberdade, é necessário que o seja de maneira a propiciar a toda gente uma vida de dignidade. Não se afirma a liberdade como um valor em si mesmo, mas como caminho pelo qual se constrói a existência humana. "Viver é muito bom", e é isso que precisa ser afirmado. A liberdade é caminho para a construção da vida, e não fim em si mesma. Isso estará mais bem afirmado na seqüência do romance $O$ tempo e o vento ${ }^{11}$, mas já pode ser percebido no texto ora analisado. Partindo para a Guerra dos Farrapos, Rodrigo não abandona sua família, mas luta por ela, para que haja possibilidade de vida em liberdade, sem opressão sobre os pequenos e fracos. Por isso volta a Santa Fé, para tomar o casarão dos Amarais, símbolo da posição conservadora. Durante essa batalha ele morre, mas sua esposa, Bibiana, poderá dizer que seu marido voltou pra casa. Para ela, de um lado, isso é a afirmação de que não foi abandonada, nem ela nem sua família, e de que estavam errados, frente àqueles que diziam que Rodrigo terminaria por abandoná-los; por outro lado, isso é também a afirmação de que a ação de Rodrigo, suas guerras e lutas são manifestações de certo compromisso vivido para com a família e com a sociedade, compromisso de ajudar a construir a história na liberdade.

A liberdade é a afirmação da aventura da vida, e isso tem muito a ver com a própria literatura. Com efeito, a literatura, sobretudo a dos romances, ocupa-se em narrar a vida, apresentando-a como uma aventura, um mergulho no desconhecido. A certeza só virá no final do romance quando, exatamente, chega-se ao final da aventura. Certezas e seguranças, pois, representam o fim da aventura e, de certa forma, o fim da história da vida. Claro que há seguranças necessárias ao ser humano, sem as quais sua vida seria impossível ou um constante perigo, mas seguranças demais acabam por tornar-se uma grande prisão ${ }^{12}$.

\footnotetext{
${ }^{11}$ Cf. Ademar Agostinho Sauthier, Liberdade e compromisso, Roma, Brill, 1989.

12 Sobre isso, cf. Antonio Manzatto, "Pour une anthropologie du risque", in A. Gesché \& P. Scolas, La foi dans le temps du risque, Paris: Cerf, 1997.
} 
Liberdade e compromisso são temas bastante trabalhados pela teologia, sobretudo a conhecida teologia latino-americana da libertação, onde se afirma não apenas a liberdade humana como caminho para a realização da vida, na luta contra toda opressão ${ }^{13}$, mas também a dimensão do compromisso, sobretudo o social ${ }^{14}$. Ele é conseqüência mesmo do ato de fé, este também vivido em liberdade, fé pela qual a pessoa compromete-se no amor dos irmãos, sobretudo os mais frágeis ${ }^{15}$, como lembra a teologia que fala da opção pelos pobres. A liberdade, assim, não é apenas um bem individual, mas dom de Deus pelo qual o humano constrói a identidade de sua vida e suas relações com as outras pessoas. No entanto, essa liberdade "teológica" sempre será processo; a estagnação se transformará em prisão, da mesma maneira como enfocado por Érico Veríssimo. Eis, portanto, a necessidade de se fazer uma "teologia da libertação", do processo contínuo de construção e conquista da liberdade, que nunca será posse definitiva, mas sempre processo, recomeço, história.

É verdade que essa visão não é nova. Já o Antigo Israel parece realizar uma reflexão nesses moldes, sobretudo no ciclo da literatura deuteronomista ${ }^{16}$. O livro dos Juízes, por exemplo, parece basear-se numa teologia da história construída nesses termos ${ }^{17}$. Quando o povo experimenta a opressão, clama a Deus que Ihes envia um libertador, um juiz; este lidera o povo em sua luta por liberdade e, com a ajuda de Deus que luta com eles, vence os inimigos, conseguindo um novo tempo de paz. O povo, então, esquecendo a necessidade de continuar sempre o processo de libertação, acomoda-se, esquece de Deus e cai novamente na opressão, Aí recomeça o ciclo, com novo clamor contra a opressão e novo pedido de ajuda de Deus. Visto assim, a liberdade é processo, nunca conquista definitiva.

\footnotetext{
${ }^{13}$ Cf., por exemplo, Gustavo Gutierrez, Teologia da Libertação, Petrópolis: Vozes, 1975; Leonardo Boff, Teologia do cativeiro e da libertação, Petrópolis: Vozes, 1980; Leonardo Boff, O caminhar da Igreja com os oprimidos, Petrópolis: Vozes, 1988.

${ }^{14}$ Cf. por exemplo, Celam (Pierre Bigo \& Fernando de Bastos Ávila), Fé cristã e compromisso social, São Paulo: Paulinas, 1982; J. Comblin, J. I. Gonzalez Faus, J. Sobrino (eds.), Cambio social y pensamiento cristiano em América Latina, Madri: Trotta, 1993.

${ }^{15} \mathrm{Cf}$, por exemplo, o célebre texto de Mt 25.

${ }^{16}$ Cf. Jean-Marie Carrière, Le livre du Deutéronome: choisir la vie, Paris: I'Atelier, 2002; Felix Garcia Lopez, Analyse littéraire de Deutéronome, Jerusalém: Franciscan Printing Press, 1978. 17 J. Alberto Soggin, Le livre des Juges, Genève: Labor et Fides, 1987; Ivo Storniolo, Como ler o livro dos Juízes, São Paulo: Paulus, 1997.
} 


\section{CONCLUSÃO}

Por isso pode-se pensar a vida, também teologicamente, como uma grande aventura no desconhecido da existência. A busca excessiva de "certezas e seguranças definitivas" leva, muitas vezes, a fé e a reflexão que dela depende, à teologia, a caminhos e situações de fechamento. $O$ medo de relativismos conduz à absolutização de processos históricos, gerando fixismo e, por conseguinte, opressão. O convite do evangelho de "avançar para águas mais profundas" foi substituído pelo desejo de segurança, de continuar junto à margem para não se correr o risco da história. Mas sem risco não há história, e sem história não há humano! A segurança do passado não possibilita fazer frente à novidade do futuro. Ora, em teologia cristã, é ação do Espírito a busca do novo, do Deus que torna novas todas as coisas, que "renova a face da Terra". A confiança na presença e na ação do Espírito deve permitir à Igreja crente a coragem de aventurar-se pelos caminhos da história humana na construção do Reino de Deus. Nesse sentido, é importante lembrar que a esperança cristã deve permanecer sempre o que ela é, ou seja, esperança escatológica ${ }^{18}$, para que não se caia na tentação de substituir o projeto do Reino de Deus simplesmente por ideais de utopias humanas, tanto de direita quanto de esquerda no que se refere ao espectro político-social. O fixismo, negação da esperança, aprisiona; o desejo e a busca de libertação fazem viver na direção do Reino pregado por Jesus.

Temos aqui, portanto, uma pequena reflexão que pode mostrar o fecundo campo de diálogo a ser desenvolvido entre a teologia e a literatura de Érico Veríssimo, sobretudo em sua grande obra, O tempo e o vento. Trata-se da convicção de que teologia e literatura podem constituir diálogo franco e enriquecedor, sem que se deixe o campo próprio de cada uma delas, ou seja, não se pede que a literatura se torne teologia, nem que esta se torne ficção, mas que estabeleçam um diálogo que possa ajudar a melhor conhecer o que representa o significado de ser humano neste mundo.

Prof. Dr. Côn. Antônio Manzatto

Diretor e Professor na Pontifícia Faculdade de Teologia Nossa Senhora da Assunção

\footnotetext{
${ }^{18}$ Cf. Jurgen Moltmann, Théologie de l'espérance, Paris: Cerf, 1970; Renold Blank, Escatologia do mundo, São Paulo: Paulus, 2001.
} 


\section{BIBLIOGRAFIA}

Ademar Agostinho Sauthier, Liberdade e compromisso, Roma: Brill, 1989.

Antonio Carlos de Melo Magalhães, Deus no espelho das palavras. São Paulo: Paulinas, 2000.

Antonio Manzatto, Teologia e literatura. São Paulo: Loyola, 1994.

Clademilson F. Paulino da Silva, Liberdade e sofrimento, São Bernardo do Campo: Dissertação de Mestrado, UMESP, 2005.

Jeni Bertoni Nimtz, O teocentrismo no barroco brasileiro; São Paulo: Tese doutoral, PFTNSA, 2003.

VÁRIOS, Teologia e literatura. Cadernos de pós-graduação 9. São Bernardo do Campo: UMESP, 1997. 